\title{
Together, we reach new heights: Swiss Sports Medicine Society (SGSM/SSMS) joins BJSM
}

\author{
Susi Kriemler, ${ }^{1}$ Andre Leumann, ${ }^{2}$ Boris Gojanovic ${ }^{3,4}$
}

The small but fine Swiss Sports Medicine Society (SSMS) has been in existence since 1949 and has about 800 members. Most of our members are general practitioners with an interest in sports medicine, and also orthopaedic surgeons, physical medicine and rehabilitation specialists or public health experts who focus on 'exercise is medicine-and prevention'. Since 1999 sports medicine in Switzerland has been a medical subspecialty that can be achieved by every physician with a medical specialty certification. 24 course days over a period of 1-2 years, a written and oral examination at the end of these and the mandatory 6-month internship in a sports medicine centre of excellence allows a high standard for our 'Swiss Sports Medicine Physician' label. These physicians ultimately govern positions as leaders of Swiss Olympic medical centres and bases, become chief medical officers for our national sporting federations or promote 'exercise is medicine' in their daily practice.

In 2015, our general assembly unanimously welcomed the proposal to become a member society partner of British Journal of Sports Medicine (BJSM), giving our members full online access to the great educational opportunities of BJSM. We are enthusiastic about this new partnership which helps us serve our members in the best interest of the population and we applaud the editors of BJSM for their excellent and inspiring work.

\section{ANNUAL MEETING IN INTERLAKEN}

The magnificent surroundings of Interlaken within the Bernese Alps offer the most perfect setting for our annual

${ }^{1}$ Epidemiology, Biostatistics and Prevention Institute, University of Zurich, Zurich, Switzerland; ${ }^{2}$ OrthoPraxis Leumann, Basel, Switzerland; ${ }^{3}$ Hôpital de La Tour, Swiss Olympic Medical Center, Geneva, Switzerland; ${ }^{4}$ Sports Medicine, Department for Human Locomotion (DAL), Lausanne University and Hospital, Lausanne, Switzerland

Correspondence to Dr Boris Gojanovic, Health and Performance Medical Director, Swiss Olympic Medical Center, Hôpital de La Tour, 1217 Meyrin, Geneva, Switzerland; boris.gojanovic@latour.ch

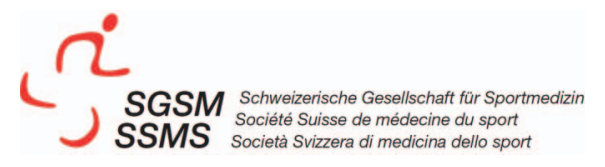

meeting on 26-28 October. We have selected the content of this issue to reflect themes that will be further developed in Interlaken.

This year we welcome medical students on a pre-day discovery tour of sports medicine through various workshops with some of our country's leading experts. Medical education is one of the essential routes through which we aim to broaden the field of sports and exercise medicine. New dedicated and young colleagues have a prime opportunity to embrace our vision of an active, healthy and performance capable population, be it through lifestyle choices or in the sports arena. New ways to contribute to education are discussed by Griffin and Shrier (see page 1101) and by Scott et al (see page 1104), while access to quality evidence through systematic reviews remains a key component in education at all levels. Weir et al (see page 1100) remind us that these summaries of evidence have room for improvement and should be trusted only in the presence of specific quality criteria.

Promoting and prescribing physical activity is one of the core missions of our society members and we are proud to present a position statement by the Canadian Association for Sports and Exercise Medicine on this very topic (see page 1109). The statement is endorsed by a total of 10 national member societies, and of course Switzerland. Dr Jane Thornton, who enjoyed living in Lausanne for two years before returning to her native Canada, did a great job at summarising the evidence and best practice. We are happy to make it our editor's choice, with free online access the world over. Exercise prescription works, prescribe it!

\section{THE SHOULDER JOINT COMPLEX}

The shoulder is frequently affected by sports injuries mainly in overhead sports, throwing disciplines and team sports (handball, tennis, baseball, javelin or volleyball). By its anatomy with a small glenoid and a large humeral head and its additional moving spaces (eg, subacromial space, scapulothoracic space, AC joint), the shoulder joint is prone to instabilities and dysfunction and overuse of stabilising and moving muscles and tendons. Thus, diagnosis and therapy are recurrent challenges in the daily life of sports physicians and they base their approach on the following pillars: diagnostics—clinical examination, radiological imaging and arthroscopy; therapy-conservative and surgical treatment options. Several articles focus on identifying differences (see pages 1115, 1124 and 1135) between diagnostic and therapeutic modalities. In the end, it is not the OR that counts, but it is the AND that leads to success. Complex pathologies cannot be solved with simple solutions. The Swiss Society of Sports Medicine will focus on that at our annual meeting 2016. A warm welcome to all!

We hope that BJSM readers will enjoy this Swiss edition and look forward to a bright future of international collaboration between all member societies. We thank BJSM for their trust and our Swiss members for their support and look forward to welcoming many of you to Interlaken with a view on the top of Europe which is-by coincidence-'the Jungfrau' (or virgin). Swiss society members-all of BJSM is now open to you-past and future issues. Spread the word to your colleagues. And please benefit from our practical links on twitter $@$ SwissSportsMed. Let us cooperate to bring more and better quality sports medicine to students, professionals and patients. Together, we reach new heights.

Follow us on twitter: Susi Kriemler @KriemlerSusi, Andre Leumann @ortho_ leumann, Boris Gojanovic@DrSportSante.

\section{Competing interests None declared.}

Provenance and peer review Commissioned; internally peer reviewed.

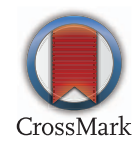

To cite Kriemler S, Leumann A, Gojanovic B. Br J Sports Med 2016;50:1099.

Accepted 22 July 2016

Br J Sports Med 2016;50:1099. doi:10.1136/bjsports-2016-096755 